\title{
HUBUNGAN ANTARA BROWNIAN MOTION (THE WIENER PROCESS) DAN SURPLUS PROCESS
}

\author{
Tohap Manurung ${ }^{1)}$ \\ ${ }^{1)}$ Program studi Matematika FMIPA Universitas Sam Ratulangi \\ Jl. Kampus Unsrat Manado, 95115 \\ Kris_ton79@yahoo.com
}

\begin{abstract}
ABSTRAK
Suatu analisis model continous-time menjadi cakupan yang akan dibahas dalam tulisan ini. Dengan demikian pengenalan proses stochastic akan sangat berperan. Dua proses akan di analisis yaitu proses compound Poisson dan Brownian motion. Proses compound Poisson sudah menjadi model standard untuk Ruin analysis dalam ilmu aktuaria. Sementara Brownian motion sangat berguna dalam teori keuangan modern dan juga dapat digunakan sebagai approksimasi untuk proses compound Poisson. Hal penting dalam tulisan ini adalah menujukkan bagaimana surplus process berdasarkan proses resiko compound Poisson dihubungkan dengan Brownian motion with Drift Process.
\end{abstract}

Kata kunci: Brownian motion with Drift process, proses surplus, compound Poisson

\section{RELATIONSHIP BETWEEN BROWNIAN MOTION (THE WIENER PROCESS) AND THE SURPLUS PROCESS}

\begin{abstract}
An analysis of continous-time models is covered in this paper. Thus, this requires an introduction to stochastic processes. Two processes are analyzed: the compound Poisson process and Brownian motion. The compound Poisson process has been the standard model for ruin analysis in actuarial science, while Brownian motion has found considerable use in modern financial theory and also can be used as an approximation to the compound Pisson process. The important thing is to show how the surplus process based on compound poisson risk process is related to Brownian motion with drift process.
\end{abstract}

Keywords: Brownian motion with drift process, surplus process, compound Poisson

\section{PENDAHULUAN}

Proses Brownian Motion, juga disebut Wiener Process atau White Noise, telah digunakan secara extensif dalam menjelaskan berbagai fenomena fisik. Ahli tumbuh-tumbuhan dari Inggris menemukan proses ini tahun 1827 dan menggunakannya untuk menjelaskan continuous irregular motion partikel yang dicelupkan dalam cairan. Tahun 1905 Albert Einstein menjelaskan gerakan ini dengan mendalilkan tubrukan abadi (perpetual collision) partikel dengan medium disekitarnya. Norbert Wiener menyajikan deskripsi analitik proses tersebut dalam suatu deret (1918). Sejak masa itu kemudian dalam banyak bidang aplikasi mulai dari mekanika quantum sampai dengan menjelaskan tingkat harga pada pasar saham proses ini telah digunakan. Proses ini menjadi pondasi model teori keuangan modern.

Dalam tulisan ini akan dibahas beberapa model proses dalam asuransi misalnya: surplus process,continous-time process, Poisson Process serta yang istimewa adalah Brownian motion with drift process. Sehingga tujuan utama tulisan ini adalah menunjukkan hubungan surplus process berdasarkan proses resiko compound poisson dihubungkan dengan Brownian motion melalui drift process. 


\section{TINJAUAN PUSTAKA}

\section{Model Aggregate Loss}

Aggregate loss adalah total kerugian yang dialami oleh pemegang polis yang harus ditanggung oleh perusahaan asuransi dalam suatu periode waktu tertentu. Metode yang digunakan untuk memperoleh aggregate loss adalah mencatat masingmasing besar klaim (payments) dan menjumlahkan semua klaim tersebut. Aggregate loss dapat dinyatakan dengan suatu peubah acak $S$. Banyak klaim dalam satu periode dari suatu portofolio dapat dinyatakan dengan peubah acak $N$. Besar masing-masing klaim dapat dinyatakan dalam peubah acak $X_{1}, X_{2}, \ldots$. Dengan demikian diperoleh suatu model collective risk

$$
S=X_{1}+X_{2}+\ldots+X_{N}, \quad N=0,1, \ldots \text { (1) }
$$

di mana $S=0$ jika $N=0$.

Asumsi-asumsi yang harus diperhatikan pada aggregate loss untuk model collective risk yaitu:

1. Diberikan $N=n$, peubah acak $X_{1}, X_{2}, \ldots$, $X_{n}$ merupakan peubah acak yang berdistribusi identik dan saling bebas.

2. Diberikan $N=n$, distribusi bersama dari peubah acak $X_{1}, X_{2}, \ldots, X_{n}$ tidak bergantung pada nilai $n$.

3. Distribusi dari peubah acak $N$ tidak bergantung kepada nilai-nilai dari peubah acak $X_{1}, X_{2}, \ldots$

\section{Proses Poisson}

Pada bagian ini ditunjukkan model yang memeriksa surplus secara kontinu dari waktu ke waktu. Karena model-model yang ada cenderung sulit menganalis, kita akan membatasi model yang digunakan, dimana model yang digunakan adalah banyak klaim( number of claims) mempunyai distribusi Poisson. Dalam hal ini akan diperkenalkan proses Poisson dan pendekatan waktu kontinu untuk model Ruin. Kita akan mempertimbangkan sifat-sifat dasar proses Poisson $; t \geq 0$ menyatakan banyak klaim dalam portofolio suatu bisnis. Jadi, $N_{t}$ adalah banyak klaim pada $(0, \mathrm{t}]$. Definisi formal proses Poisson adalah sebagai berikut Definisi 1 Proses banyak klaim ${ }_{t} ; t \geq 0$ adalah proses Poisson dengan nilai $\lambda>0$ jika kondisi-kondisi berikut terpenuhi:

1. $\mathrm{N}_{0}=0$

2. Proses banyak klaim mempunyai stationary and independent increments.

3. Banyak klaim dalam interval selang $t$ adalah Poisson yang terdistribusi dengan mean $\lambda t$. yaitu, untuk semua $s, t>0$ diperoleh

$$
\operatorname{Pr} \boldsymbol{N}_{t+s}-N_{s}=n=\frac{Q^{2} t_{-}^{\lambda} e^{-\lambda t}}{n !}, n=0,1, \ldots . .
$$

Stasionary increments adalah distribusi banyak klaim dalam interval tetap hanya bergantung dalam panjang interval atau dikatakan tidak ada trend effect.

Independent Increments adalah banyak klaim dalam interval secara statistik bebas dari banyak klaim pada setiap interval sebelumnya (not overlapping the present interval).

\section{Proses surplus}

Surplus Process merupakan salah satu model proses asuransi. Surplus process ditulis sebagai c (atau mungkin juga dalam versi discrete-time, $\left.\quad \boldsymbol{W}_{t}=0,1,2, \ldots\right)$, yang mengukur surplus dari portofolio pada saat t. Pada saat $\mathrm{t}=0, u=U_{0}$, disebut initial surplus. Dalam hal ini, surplus dalam ilmu akuntansi menyatakan excess funds yang tidak diperlukan jika portofolio diakhiri pada hari ini. Untuk hal yang 'ongoing' nilai positif menyajikan perlindungan tehadap kemalangan. Surplus pada saat $\mathrm{t}$ adalah

$$
U_{t}=U_{0}+P_{t}+S_{t},
$$

dimana $t \geq 0$ adalah proses premi (premium process) yang mengukur setiap premium (net of expenses) yang dikumpulkan sampai waktu $\mathrm{t}$, dan $\$ t \geq 0$ adalah proses rugi (loss process), yang mengukur setiap kerugian yang dibayarkan sampai waktu t. Berikut ini adalah observasinya:

1. $\mathrm{P}_{\mathrm{t}}$ dapat dituliskan atau premi-premi yang diperoleh, yang sesuai

2. $\mathrm{S}_{\mathrm{t}}$ dapat dibayarkan atau kerugiankerugian yang terjadi, yang sesuai

3. $\mathrm{P}_{\mathrm{t}}$ tergantung pada $\mathrm{S}_{\mathrm{u}}$ untuk $u<t$. Sebagai contoh, deviden berdasarkan kerugian-kerugian masa lalu yang dapat mengurangi premi sekarang. 
Adalah mungkin, meskipun tidak perlu, untuk memisahkan komponen frekuensi dan severity dari $S_{t}$. Misalkan ; $; t \geq 0$ menjadi proses klaim yang mencatat banyak klaim pada saat t. Kemudian misalkan $S_{t}=X_{1}+\ldots .+X_{N_{t}}$. Barisan

$\mathbb{N}_{1}, X_{2}, \ldots$ tidak harus termasuk variabel independent and identically distributed (i.i.d). Akan tetapi, jika i.i.d dan barisannya independen pada $\mathrm{N}_{t}$ untuk semua $t$, maka $S_{t}$ mempunyai sebuah distribusi compound . Ada dua kasus spesial surplus process yaitu:

\section{Model discrete-Time}

Misalkan kenaikan (increment) pada surplus Process selama tahun $t$ didefinisikan sebagai

$W_{t}=P_{t}-P_{t-1}-S_{t}+S_{t-1}, t=1,2, \ldots$.

Maka perkembangan surplus adalah

$U_{t}=U_{t-1}+W_{t}, t=1,2$

Akan relatif mudah mempelajari distribusi $\quad \boldsymbol{B}_{t} ; t=0,1, \ldots$ yang diberikan , dimana peubah acak $\mathrm{W}_{\mathrm{t}}$ adalah independen untuk baik $\mathrm{W}_{\mathrm{t}} \mathrm{s}$ atau hanya tergantung pada nilai $U_{t-1}$. Ketergantungan $W_{t}$ pada $U_{t-1}$ memperbolehkan untuk membayar deviden berdasarkan surplus di akhir tahun sebelumnya (karena $\mathrm{W}_{\mathrm{t}}$ bergantung pada $\mathrm{P}_{\mathrm{t}}$ ).

\section{Model Continous-Time}

Dalam kebanyakan kasus sulit untuk menganalisis model continous-time. Hal ini menyebabkan distribusi gabungan harus dikembangkan di setiap titik waktu, tidak hanya pada himpunan titik-titik waktu yang terhitung(countable). Satu model yang telah extensive di analisis adalah proses klaim compound poisson dimana premi-premi dikumpul pada nilai yang bukan acak kontinu konstan,

$$
\begin{aligned}
& P_{t}=(1+\theta) E\left(S_{1}\right) t, \\
& \text { dan total loss process adalah } \\
& S_{t}=X_{1}+\ldots .+X_{N_{t}} \text { dimana } \\
& \text { adalah Poisson process. }
\end{aligned}
$$

\section{Proses resiko Brownian Motion}

Tujuan dari tulisan ini adalah untuk menunjukkan hubungan antara Brownian motion (Wiener Process) dan surplus process $\boldsymbol{G}_{t} ; t \geq 0$, dimana

$$
U_{t}=u+c t-S_{t}, \quad t \geq 0
$$

dan $\quad t \geq 0$ adalah total loss process yang didefinisikan oleh

$$
S_{t}=X_{1}+X_{2}+\ldots .+X_{N t}, \quad t \geq 0,
$$

dimana $\quad ; t \geq 0$ adalah proses Poisson dengan nilai $\lambda$ dan $S_{t}=0$ when $N_{t}=0$.

Pada sub bagian sebelumnya diasumsikan bahwa kerugian-kerugian individu $\mathbb{X}_{1}, X_{2}, \ldots$ adalah distribusi identik dan saling bebas peubah acak positif dimana funsi pembangun momen ada. Surplus Process $\boldsymbol{W}_{t} ; t \geq 0$, adalah naik kontinu (increasing continuously) dengan kemiringan (slope) c, Nilai premi per unit waktu, dan downward jumps berturut-turut dari $\mathbb{Z}_{1}, X_{2}, \ldots$. pada random jump times $\boldsymbol{\aleph}_{2}, \ldots$.

Misalkan

$Z_{t}=U_{t}-u=c t-S_{t}, \quad t \geq 0$.

Sehingga $\mathrm{Z}_{0}=0$. Karena $S_{t}$ mempunyai distribusi compound, process $\boldsymbol{Z}_{\mathbf{a}} ; t \geq 0$ mempunyai

$$
\begin{aligned}
E\left(Z_{t}\right) & =c t-E\left(S_{t}\right) \\
& =c t-\lambda t E(X)
\end{aligned}
$$

dan varians

$$
\operatorname{Var}\left(Z_{t}\right)=\lambda t E\left(X^{2}\right) .
$$

Selanjutnya, berikut ini akan diperkenalkan proses stokastik yang sesuai berdasarkan Brownian motion

Definisi 2. Proses stochastic untuk continuous-time $; t \geq 0$ adalah Brownian process jika:

1. $\mathrm{W}_{0}=0$;

2. $; t \geq 0$ mempunyai stasionary and independent increments; dan

3. Untuk setiap $\mathrm{t}>0, \mathrm{~W}_{\mathrm{t}}$ adalah terdistribusi normal dengan mean 0 dan varians $\sigma^{2} t$.

Definisi 3. Proses stochastic continuoustime $; t \geq 0$ disebut proses Brownian motion with drift jika memenuhi sifat-sifat dari proses Brownian motion kecuali $\mathrm{W}_{\mathrm{t}}$ mempunyai mean $\mu t$ dan bukan 0 untuk $\mu>0$ 


\section{PEMBAHASAN}

Pada bagian ini akan ditunjukkan bagaimana surplus process (8) berdasarkan proses resiko Poisson dihubungkan dengan Brownian motion dengan drift process. Kita akan mengambil limit dari proses (8) sebagai ekpektasi bilangan downward jumps menjadi besar dan secara simultan besar lompatan menjadi kecil. Karena Brownian motion dengan drift process dikarakterisasi oleh mean $\mu$ yang sangat kecil dan varians

$\sigma$ yang sangat kecil , kita mendorong fungsi mean dan varians menjadi sama untuk dua proses. Dalam hal ini, Brownian motion dengan drift dapat dianggap sebagai aproksimasi terhadap compound Poisson berdasarkan surplus process. Sama halnya, proses compound Poisson dapat digunakan sebagai aproksimasi untuk Brownian motion.

Misalkan

$$
\mu=c-\lambda E(X)
$$

dan

$$
\sigma^{2}=\lambda E\left(X^{2}\right)
$$

menunjukkan mean dan varians yang sangat kecil dari Brownian motion dengan drift pocess. Kemudian

$$
\lambda=\frac{\sigma^{2}}{E\left[X^{2}\right]}
$$

dan

$$
c=\mu+\sigma^{2} \frac{E[X]}{E\left[X^{2}\right]} .
$$

Selanjutnya, untuk mencapai limit, kita membuat lompatan (jump) nilai $\mathrm{X}$ sebagai suatu bagian skala beberapa peubah acak $\mathrm{Y}$ lainnya., sehingga $\mathrm{X}=\alpha \mathrm{Y}$, dimana $\mathrm{Y}$ mempunyai mean dan varians tetap. Kemudian

$$
\lambda=\frac{\sigma^{2}}{E\left[Y^{2}\right]} \cdot \frac{1}{\alpha^{2}}
$$

dan

$$
c=\mu+\sigma^{2} \frac{E[Y]}{E\left[Y^{2}\right]} \frac{1}{\alpha}
$$

Maka agar $\lambda \rightarrow \infty$, ditentukan $\alpha \rightarrow 0$.

Karena proses $\$ t \geq 0$ adalah proses continuous-time yang stasioner dan independent increment, sehingga proses $\boldsymbol{Q}_{t} ; t \geq 0$ and $; t \geq 0$. Hal ini kemudian juga menjadi kasus limiting process. Karena $Z_{0}=0$, kita hanya perlu membentuknya, bahwa untuk setiap $t$, dalam limit, $Z_{\mathrm{t}}$ terdistribusi normal dengan mean $\mu t$ dan varians $\sigma^{2} t$ menurut definisi 2 dan definisi 3. Kita akan menyelesaikan ini dengan memperhatikan fungsi pembangun momen (momen generating function) dari

$$
\begin{aligned}
M_{Z_{t}}(r) & =M_{c t-S_{t}}(r) \\
\mathrm{Z}_{\mathrm{t} .} & \left.=E \exp \left[r\left(c t-S_{t}\right)\right]\right\} \\
& =\exp \left(r_{c} c+\lambda\left[M_{X}(-r)-1\right]\right\}
\end{aligned}
$$

Maka

$$
\begin{aligned}
& \frac{\ln M_{Z_{t}}(r)}{t} \\
= & r c+\lambda\left[M_{X}(-r)-1\right] \\
= & r[\mu+\lambda E(X)] \\
& +\lambda\left[1-r E(X)+\frac{r^{2}}{2 !} E\left(X^{2}\right)+\frac{r^{3}}{3 !} E\left(X^{3}\right)+\ldots-1\right] \\
= & r \mu+\frac{r^{2}}{2} \lambda E\left(X^{2}\right)-\lambda\left[\frac{r^{3}}{3 !} E\left(X^{3}\right)+\frac{r^{4}}{4 !} E\left(X^{4}\right)+\ldots\right] \\
= & r \mu+\frac{r^{2}}{2} \sigma^{2}-\lambda \alpha^{2}\left[\alpha \frac{r^{3}}{3 !} E\left(Y^{3}\right)-\alpha^{2} \frac{r^{4}}{4 !} E\left(Y^{4}\right)+\ldots\right] \\
= & r \mu+\frac{r^{2}}{2} \sigma^{2}-\sigma^{2}\left[\alpha \frac{r^{3}}{3 !} \frac{E\left(Y^{3}\right)}{E\left(Y^{2}\right)}-\alpha^{2} \frac{r^{4}}{4 !} \frac{E\left(Y^{4}\right)}{E\left(Y^{2}\right)}+\ldots\right]
\end{aligned}
$$

Karena $\alpha \rightarrow 0$, kita mempunyai

$\lim _{\alpha \rightarrow 0} M_{Z_{t}}(r)=\exp \left(r \mu t+\frac{r^{2}}{2} \sigma^{2} t\right)$,

dimana mgf dari distribusi normal dengan mean $\mu t$ dan varians $\sigma^{2} t$. Ini menunjukkan bahwa limiting process adalah Brownian motion dengan drift process. Karena banyak titik jump meningkat dengan tak hingga, proses menjadi nowhere differentiable. Sifat lain dari proses Brownian motion adalah bahwa path nya adalah fungsi kontinu dari $\mathrm{t}$ dengan peluang 1 . Secata intuitif, ini terjadi karena besar lompatan menjadi kecil saat $\alpha \rightarrow 0$.

Akhirnya, total jarak yang dilewati pada $(0, \mathrm{t}]$ oleh proses $\mathrm{U}_{\mathrm{t}}$ adalah

$$
\begin{aligned}
D & =c t+S_{t} \\
& =c t+X_{1}+\ldots+X_{N_{t}},
\end{aligned}
$$


yang mempunyai nilai ekpektasi

$$
\begin{aligned}
& E[D]=c t+\lambda t E(X) \\
& =t\left[\mu+\sigma^{2} \frac{E[Y]}{E\left[Y^{2}\right]} \cdot \frac{1}{\alpha}+\sigma^{2} \frac{E[Y]}{E\left[Y^{2}\right]} \cdot \frac{1}{\alpha}\right] \\
& =t\left[\mu+2 \sigma^{2} \frac{E[Y]}{E\left[Y^{2}\right]} \cdot \frac{1}{\alpha}\right] .
\end{aligned}
$$

Nilai tersebut menjadi tak hingga pada saat $\alpha \rightarrow 0$. Jadi,

$$
\lim _{\alpha \rightarrow 0} E[D]=\infty .
$$

Artinya bahwa ekpektasi jarak yang dilewati dalam interval waktu berhingga adalah besar tak hingga.

\section{KESIMPULAN}

Karena $Z_{t}=U_{t}-u$, kita dapat menambahkan hanya nilai u (initial surplus) untuk Brownian motion dengan drift process dan kemudian meggunakan $\lambda=\frac{\sigma^{2}}{E\left[X^{2}\right]}$ dan $c=\mu+\sigma^{2} \frac{E[X]}{E\left[X^{2}\right]}$ untuk Mengembangkan aproksimasi proses $Z_{t}=U_{t}-u=c t-S_{t}, \quad t \geq 0 . \quad$ Tentu saja, nilai yang lebih besar $\lambda$ lompatan yang lebih kecil menjadi aproksimasi yang lebih baik. Untuk blok police asuransi yang sangat besar (sebagai contoh, seluruh perusahaan asuransi), hal ini akan lebih tepat. Dalam kasus ini, peluang ruin utama dan distribusi waktu sampai ruin dengan mudah diperoleh dari aproksimasi Brownian motion dengan drift process.

\section{DAFTAR PUSTAKA}

Karlin, S., Taylor, H.M. (1975): A First Course in Stochastic Processes. Second Edition.

Klugman, Stuart A., Panjer, Harry H., dan Willmot, Gordon E. (2004):Loss Models from Data to Decisions. Second Edition. New Jersey: John Wiley \& Sons.

Rieske. H.,Sapto W.I, Proses stokastik, catatan kuliah (MA-4192), penerbit ITB.

Ross, S. (1996): Stochastic Processes, Second Edition., New York: John Wiley \& Sons. 